\title{
POR UM HISTÓRICO DA VIOLÊNCIA DE GÊNERO NA AMÉRICA LATINA E CARIBE: "POSSIBILIDADES" PARA AS PESQUISAS EM EDUCAÇÃO SEXUAL
}

\author{
POR UNA HISTORIA DE VIOLENCIA DE GÉNERO EN AMÉRICA LATINA Y EL \\ CARIBE: "POSIBILIDADES" PARA LA INVESTIGACIÓN EN EDUCACIÓN SEXUAL
}

FOR A HISTORY OF GENDER VIOLENCE IN LATIN AMERICA AND THE CARIBBEAN: "POSSIBILITIES" FOR RESEARCH IN SEXUAL EDUCATION

\author{
Claudionor Renato da SILVA ${ }^{1}$ \\ Paulo Rennes Marçal RIBEIRO ${ }^{2}$ \\ Solange Aparecida de Souza MONTEIRO ${ }^{3}$
}

RESUMO: A violência de gênero é um tema importante para os estudos da Educação Sexual. Debater o tema na macrorregião da América Latina e Caribe alcança ainda maior importância quando se propõe a pensar caminhos de investigação para jovens pesquisadoras(es). Este é o objetivo deste pequeno texto de natureza bibliográfica: indicar possibilidades de um estudo sobre uma historicidade da violência de gênero na macrorregião. São propostas duas possibilidades investigativas: um ponto de partida em documentos internacionais oficiais; outro ponto de partida são as pesquisas que falam da violência de gênero, desde os anos 1970 com teorias que tentaram explicar a violência de gênero, como o patriarcado, as epistemologias do sul, como exemplos. Conclui-se o estudo com encaminahamentos e incentivos para estas investigações na tentativa de se encontrar uma importante lacuna: a violência de gênero, antes da presença europeia, o que demanda que uma terceira possibilidade de estudos na área da Educação Sexual seja pautada na etno-história e na antropologia. A terceira possibilidade é ainda uma construção a ser desenvolvida na área da Educação Sexual.

PALAVRAS-CHAVE: História. Violência de gênero. Educação sexual. América latina e caribe.

RESUMEN: La violencia de género es un tema importante para los estudios sobre educación sexual. Debatir el tema en el macrorregión de América Latina y el Caribe es aún más importante cuando se propone pensar en trayectorias de investigación para jóvenes investigadores. Este es el propósito de este breve texto de carácter bibliográfico: indicar posibilidades para un estudio sobre la historicidad de la violencia de género en el macrorregión. Se proponen dos posibilidades de investigación: un punto de partida en documentos internacionales oficiales; otro punto de partida es la investigación que habla de

${ }^{1}$ Universidade Federal de Jataí (UFJ), Jataí - GO - Brasil. Docente e Pesquisador do Curso de Pedagogia (Unidade de Educação) e Programa de Pós-Graduação em Educação (PPGE - Unidade de Ciências Humanas). Doutorado em Educação Escolar (UNESP). ORCID: http://orcid.org/0000-0003-1693-4804. E-mail: claudionorsil@gmail.com

${ }^{2}$ Universidade Estadual Paulista (UNESP), Araraquara - SP - Brasil. Professor Associado no Departamento de Psicologia da Educação e Docente dos Programas de Pós-graduação em Educação Sexual e Educação Escolar. Livre-Docente em Sexologia e Educação Sexual (UNESP). E-mail: paulorennes@gmail.com

${ }^{3}$ Universidade Estadual Paulista (UNESP). Araraquara - SP - Brasil. Doutoranda no Programa de Pós-graduação em Educação Escolar. ORCID: https://orcid.org/0000-0002-1640-0266. E-mail: solmonteiro@ifsp.edu.br

RPGE- Revista on line de Política e Gestão Educacional, Araraquara, v. 24, n. esp. 3, p. 1809-1824, nov. 2020. e-ISSN:1519-9029 
violencia de género, desde la década de 1970 con teorías que intentaron explicar la violencia de género, como el patriarcado, las epistemologías del sur, como ejemplos. El estudio concluye con referencias e incentivos para estas investigaciones en un intento por encontrar una brecha importante: la violencia de género, ante la presencia europea, que exige que una tercera posibilidad de estudios en el área de Educación Sexual sea guiada por etno-historia y antropología. La tercera posibilidad es aún una construcción por desarrollar en el área de Educación Sexual.

PALABRAS CLAVE: Historia. La violencia de género. Educación sexual. América latina y el caribe.

ABSTRACT: Gender-based violence is an important topic for studies on sexual education. Debating the theme in the macro-region of Latin America and the Caribbean is even more important when it proposes to think about research paths for young researchers. This is the purpose of this short text of a bibliographic nature: to indicate possibilities for a study on the historicity of gender violence in the macro-region. Two investigative possibilities are proposed: a starting point in official international documents; another starting point are the researches that speak of gender violence, since the 1970s with theories that tried to explain gender violence, such as patriarchy, southern epistemologies, as examples. The study concludes with referrals and incentives for these investigations in an attempt to find an important gap: gender violence before the European presence, which demands that a third possibility of studies in the area of Sexual Education be guided by ethno-history and anthropology. The third possibility is still a construction to be developed in the area of Sexual Education.

KEYWORDS: History. Gender-based violence. Sex education. Latin america and caribbean.

\section{Introdução}

A pergunta de pesquisa que abre este artigo é a seguinte: é possível uma construção histórica da violência de gênero na América Latina (AL) e Caribe (CA), sob um enfoque na Educação Sexual? E, por que um histórico da violência de gênero nesta macrorregião, tão diversa e tão complexa, geográfica, idiomática, político-econômica etc.?

Partimos da concepção de que a violência de gênero é um dispositivo de sexualidade que, como afirma Foucault (1999), produziu uma verdade sobre o sexo que, por sua vez, implicou na "naturalização" desta violência contra a mulher, numa biopolítica masculina e patriarcal.

Para retirar ou combater essa verdade sobre o sexo, deve se iniciar pelas tecnologias de poder que subsidiam ou dão forças para esse dispositivo de sexualidade que chamaremos, por hora, de "dispositivos de violência sexual contra a mulher".

Foucault (1999) nos dá pistas para retirada desta verdade e para o combate a este dispositivo, no âmbito da Educação Sexual: recursos da história, da teoria da história e da 
política da história (biopoder). Se assume essa ideia foucaultiana para este estudo sobre a violência de gênero na macrorregião.

Para que haja uma investida em Educação Sexual no âmbito das discussões da violência de gênero, a história (primeiro plano) e a teoria da história, ou teorias que explicam o fenômeno histórico (segundo plano), bem como, a política da história ou os contextos de políticas que são combativas ao biopoder constituído e instituído "historicamente" (terceiro plano) são fundamentais, não só as análises, mas, sobretudo, a construção de ferramentas de contra poder no desenvolvimento de pesquisa na área da Educação Sexual.

Na tentativa de começar a responder à questão da pesquisa, sobremodo complexa, podese afirmar que a história do "aparecimento" ou "desenvolvimento" da violência de gênero na AL e CA - mas também, para os seus estudos de políticas combativas - é de origem colonial, patriarcal, de dominação, predominantemente europeizante. Os estudos acadêmicos foram, talvez, o primeiro investimento em direção a essa conclusão. Mas, pouco se pode dizer, pelos estudos em evidência, sobre a vida das mulheres no contexto anterior à "presença" ou "visita" europeia, para o que um estudo mais aprofundado, tanto etnográfico quanto arqueológico, seria de grande utilidade para os estudos em Educação Sexual.

Um caminho também possível na construção de uma resposta para a problemática levantada no artigo é resultante dos posicionamentos dos órgãos internacionais que passaram "tardiamente" a considerar as demandas de violência contra mulheres e, mais recentemente, contra pessoas LGBT - a multiplicidade e diversidade da violência de gênero, com demarcações específicas e temporais.

Tais órgãos, principalmente a ONU e a CEPAL, iniciaram grupos de trabalho, geralmente, com a consulta a pesquisadoras(es) da macrorregião, que estudavam a história da violência contra a mulher, desde a ocupação europeia nestas terras, originalmente, de povos e nações que, correntemente, chamamos de "povos indígenas", mas que possuem seus próprios nomes ancestrais até a contemporaneidade.

Estes estudos da academia, que são anteriores aos órgãos mencionados, já estavam presentes em muitas publicações datadas dos anos 1980, sobretudo, com pesquisadoras e militantes feministas, em toda a América Latina, a princípio, com influências de Lerner (1986) e outras autoras internacionais de língua inglesa. Particularmente, no Brasil, Mariza Corrêa (CÔRREA, 1983) e Heleieth Saffioti (SAFFIOTI, 2004). Já nos anos 1990, Saffioti e Almeida, (1995) e tantas outras formaram o que se pode chamar de "primeira linha de frente" nos estudos brasileiros sobre a violência de gênero. 
O histórico da violência de gênero é sempre muito negativo, geralmente, ligado a históricos de políticas públicas tardias, como afirmam Strey, Azambuja e Jaegger (2004).

As mulheres destes povos e nações destas terras da macrorregião em estudo sofreram todo o tipo de violência; foram mulheres maltratadas - utilizando uma palavra muito branda -; povos e nações totalmente dizimados. E, depois, sob a escravidão negra e a formação dos Estados-Nação na AL e CA, uma história de poder "sexual" tão ampla e fortemente acentuada, ao mesmo tempo tão "silenciada", essa história "única" de discursos e "verdades" sobre as relações de poder "sexuais" e desiguais, entre homens e mulheres. Se apoia tais considerações, por exemplo, em Lerner (1986), Fregoso e Bejarano (2010), Steves et al. (2017), Priore (2012), Fernández (2012), Pita (2015) e Steves et al. (2017).

Em contraponto à perspectiva negativa, os encaminhamentos mais amplos desta produção textual é considerar os aspectos positivos dos estudos históricos sobre a violência de gênero, nesta macrorregião, que se vinculam a uma Educação Sexual educativa e formativa. Sobretudo, preventiva e de diagnósticos, que redundam em efetividades de políticas em sexualidade humana contra a violência de gênero, contra meninas e mulheres.

Diante destas considerações, pode-se dizer que o objetivo geral deste estudo é demonstrar que a história da violência de gênero na macrorregião em estudo é fruto de um histórico de dominação, cultural, étnica, política etc., pela força (poder, no conceito foucaultiano).

Especificamente, pode-se pontuar que o texto objetiva: 1) demonstrar o fator histórico de abordagem foucaultiana para o desenvolvimento do tema da violência de gênero na AL e CA, que se considera fundamental para a emancipação e o enfrentamento contra a violência de gênero, contra mulheres e meninas e, num outro estudo possível, se abordar a violência, contra pessoas LGBT, por meio de políticas de Estado; 2) apontar a história, ontem e hoje, como propulsora de mudanças culturais, sociais, na formatação de uma multiplicidade de dimensões analíticas, sobretudo, políticas de Educação Sexual (em sexualidade humana), dos impactos da violência de gênero, na busca de novos direcionamentos sociais que se pautem pela Democracia, pela cidadania e liberdades individuais - excluindo-se o que se pode dizer, dos modus de vivência entre homens e mulheres nas sociedades antes da "presença europeia", o que demandaria, e demanda, estudos ainda mais específicos e desafiadores para a Educação Sexual, nos estudos sobre a violência de gênero contra meninas e mulheres. 


\section{Proposta de uma construção histórica da violência de gênero na macrorregião}

Qual a posição teórica de "história" - na acepção foucaultiana - no desenvolvimento de uma possível teoria da violência de gênero nos estudos da Educação Sexual, com propósito de subsidiar pesquisas na macrorregião?

Se assume neste trabalho que a história da violência contra a mulher, para a área da Educação Sexual, nesta macrorregião, seja uma história que,

[...] de agora em diante, por interrogações de outro tipo: Que estratos é preciso isolar uns dos outros? Que tipos de séries instaurar? Que critérios de periodização adotar para cada uma delas? Que sistema de relações (hierarquia, dominância, escalonamento, determinação unívoca, causalidade circular) pode ser descrito entre uma e outra? Que séries de séries podem ser estabelecidas? E em que quadro, de cronologia ampla, podem ser determinadas sequências distintas de acontecimentos? (FOUCAULT, 2008, p. $4)$.

A História (no viés foucaultiano) da violência de gênero na AL e CA deve ser, na proposta desta obra, numa concepção de Educação Sexual, uma História embasada nos discursos, no poder; uma História "acronológica"; uma História que traz dos "silêncios" tendenciosos, as vozes e discursos ocultados; "atos e liminares epistemológicos" (proposta bachelardiana), deslocamentos e transformações (proposta de Georges Canguilhem): valem não o cronológico, mas as descontinuidades, as inflexões. Deste modo, novas "validações" para as histórias de poder, "machas" que ainda matam mulheres, matam e violentam meninas crianças, adolescentes e jovens

A História ou o fator histórico para a sexualidade, proposta no pensamento de Michel Foucault - em que se pretende pautar um ou mais subsídios aos estudos em Educação Sexual, para o debate sobre a violência de gênero na $\mathrm{AL}$ e CA, - inicia-se, um pouco antes de " $A$ Arqueologia do Saber" (FOUCAULT, 2008); considera-se, obviamente, o conjunto da obra deste autor, especialmente, o volume I de a "História da Sexualidade I" (Vontade de Saber) (FOUCAULT, 1999) e também as especificidades de “A ORDEM DO DISCURSO” (Foucault, 2004) e outros textos, em suas diversas dinâmicas de produção, características de Foucault, que deixa um legado para a Educação Sexual, em específico, na construção de uma visão histórica, suficientemente crítica, pautada no discurso, no poder, que uma vez transposto para o tema em destaque, a violência de gênero, a violência contra mulheres e $\mathrm{LGBT}^{4}$, obriga,

${ }^{4}$ Para uma história da violência de gênero para com as pessoas LGBT se exigem outras fontes e outras vertentes de análise e, talvez, pela metodologia histórica foucaultiana aqui escolhida, que se desdobre em novos estudos da área da Educação Sexual, sob as referência em Daniel Borrilo e Judith Butler, por exemplo. 
pesquisadoras(es), como especialistas da área, a tecer, ainda que brevemente, o modus de descrever e analisar essa História, como a história de um dispositivo geral de sexualidade.

Os espaços deste artigo não permitirão o aprofundamento da perspectiva histórica foucaultiana aqui comentada brevemente, mas se perceberá, ao longo da apresentação das fontes de análise, para uma construção da História da violência de gênero na AL e CA (legislações internacionais e teorias explicativas da violência contra mulheres) que esta História apresentada por autores contemporâneos não é mais, somente, uma História de resultantes da colonização europeia, perpassa, como apontaram Cruz et al. (2000), as guerras internas em cada Estado-nação, em vários períodos, inclusive, na contemporaneidade, bem como revoluções ditatoriais e a instauração de governos direitistas-democráticos que trouxeram desestabilizações sociais e culminaram também em maiores desigualdades de gênero, principalmente nas classes menos favorecidas economicamente, sobretudos as ascendentes dos povos e nações indígenas da macrorregião. Talvez, o auge do combate à violência de gênero ou políticas anti-feminicídio na América Latina e Caribe tenha obtido um destaque histórico com governos populares ou de gestão de mulheres, sobretudo na entrada dos anos 2000.

Algumas dificuldades na construção de um histórico (de abordagem foucaultiana) da violência de gênero, na macrorregião, no âmbito da área da Educação Sexual são admitidas neste trabalho, a saber: 1) a falta de trabalhos específicos, ao mesmo tempo, amplos, que sejam pontos de partida, subsídios, para falar da violência do ponto de vista histórico; faltam obras específicas e aprofundadas, sob um enfoque da História, particularmente, em Michel Foucault - daí a inovação deste artigo e porque ele se direciona para formatar subsídios para os estudos da Educação Sexual na macrorregião; 2) A ausência de estudos sobre violência de gênero no Caribe, como já se indicou em outros trabalhos (SILVA, 2018; MONTEIRO; SILVA; RIBEIRO, 2020); faltam, sobretudo, pesquisadoras(es) do Caribe que discutam estas questões seja no âmbito da CEPAL ou outras fontes, que incluam as fontes acadêmicas e que, possivelmente, avancem para status de estudos sobre a violência de gênero anterior à "presença" europeia no continente.

De qualquer forma, a proposta deste artigo é delimitar, um possível construto histórico da violência de gênero em duas possibilidades:

- $\quad$ Possibilidade 1: partir das produções dos órgãos internacionais da ONU e da CEPAL, com resoluções, estudos empíricos e estatísticos, encomendados por especialistas; Declarações em eventos por toda a macrorregião, dentre outras ações. 
- $\quad$ Possibilidade 2: partir do histórico da colonização europeia na AL e Caribe, com todas as diversidades e complexidades existentes (região "macro-diversa"), desde o idioma "implantado" até a "cultura" desenvolvida nestes espaços e na atualidade; uma análise breve das teorias que se debruçam sobre o tema da violência de gênero na macrorregião, como a teoria do colonialismo (genocídio colonial, o colonialismo de gênero), o patriarcado e as epistemologias do sul, por exemplo.

Estas duas possibilidades são as seções centrais do artigo. Nas considerações finais se fazem as apresentações de alguns desafios e subsídios, que o presente artigo constrói, para o incentivo de pesquisas que busquem respostas, no histórico da violência de gênero na AL e CA e na estruturação foucaultiana de História, que possibilitem, para a área da Educação Sexual, a formulação de estudos mais abrangentes das "histórias" não contadas, das "histórias" silenciadas e das histórias "sublinhares" da violência de gênero contra meninas e mulheres.

\section{As possibilidades históricas para a violência de gênero na América Latina e Caribe}

Possibilidade 1: os dados de pesquisas e estatísticas de órgãos internacionais - ONU, CEPAL, CLADEM - e diversas fontes de dados em "redes" e observatórios

Do aporte da História na perspectiva foucaultiana se opta por iniciar um histórico da violência de gênero na AL e CA a partir dos órgãos internacionais, ONU, CEPAL e CLADEM, reiterando que o processo desta construção é devido ao movimento feminista mundial que, em cada local da macrorregião, ou, pelo menos em alguns destes países, se deu de modos diferentes e, por isso mesmo, a análise e o construto histórico, não pode se dar linearmente. De qualquer modo, para a Educação Sexual, é necessário um “demarcar” e a escolha é pelos documentos oficiais dos órgãos internacionais incumbidos de delinear políticas e financiamentos para as questões de direitos humanos e liberdades cidadãs relativas às mulheres, ainda que tenham sido tardias, em virtude, de publicações e estudos, sobretudo, pelas feministas, serem bem anteriores às suas ações, de coordenação temática e de gestão de políticas em rede.

Começando pela ONU, as preocupações dos estados-nação com as mulheres só começaram no século XX e não representavam uma totalidade, senão, uns poucos países, começando pelo direito ao voto.

Dentre os eventos, na década dos anos 1970 podem ser citadas a I Conferência Mundial sobre a Condição Jurídica da Mulher, em 1975, na cidade do México e a mesma conferência, 
em Nairóbi, no ano de 1985 em que se escreve a Declaração sobre a Eliminação da Violência contra a Mulher.

Das produções destes eventos e coordenações de órgãos internacionais, se convenciona chamar de Violência de Gênero como qualquer ação contra a mulher que lhe cause, em último estágio, a morte, ou, caso contrário, danos ou sofrimentos, físico, sexual ou psicológico.

Ainda na amplitude desta definição advinda dos documentos internacionais, como a Convenção de Belém do Pará, pode-se compreender a violência de gênero como tudo aquilo que sofre a mulher em razão ou em consequência de ser mulher.

Em 1993, a ONU lança a Resolução Sobre a Eliminação da Violência Contra a Mulher (Resolução da Assembleia Geral 48/104 de 20 de dezembro de 1993). Um primeiro instrumento jurídico contra a violência contra a mulher e um primeiro pilar histórico.

A ONU institui a partir da Comissão de Direitos Humanos uma "Relatoria Especial sobre a Violência contra a Mulher, suas causas e consequências”. Esta Comissão é responsável por várias reiterações da Resolução 48/104, como, por exemplo, a Resolução 62/133 de 7 de fevereiro de 2008 (FERNÁNDEZ, 2012).

A última Conferência Mundial sobre a Condição Jurídica da Mulher ocorreu em Beijing (1995) quando se consolidam algumas questões importantes para o empoderamento de mulheres no mundo: a igualdade entre homens e mulheres; a violência de gênero como "feridora" dos princípios dos Direitos Humanos; a obrigação de estados-nação em se responsabilizarem pela proteção de meninas e mulheres contra toda a violência.

O andamento das resoluções da ONU após 1995 demonstraram o avanço do entendimento "político" e de saúde pública, bem como, de segurança pública em tudo que se relaciona ao termo "violência de gênero" e toda a sua abrangência.

A cada Resolução, vão incorporando, lentamente, as meninas (crianças, adolescentes e jovens), bem como, aportando em temas como a prostituição e o tráfico sexual de mulheres. São importantes temas para a Educação Sexual, sob o viés temático da violência de gênero. Somam-se os temas da violência contra mulheres migrantes (fenômeno da migração na AL e CA).

Estas Resoluções, bem como, os diversos encontros e "acordos" políticos ao longo dos anos contribuíram para a elaboração de leis importantes de combate à violência de gênero em alguns países da AL e CA, como as apresentadas no Quadro 1, sobretudo e, particularmente, após os anos 2000. 
Quadro 1 - Leis nacionais para eliminação da Violência contra Mulheres

\begin{tabular}{|c|c|c|}
\hline PAÍS & LEI & ANO \\
\hline Brasil & Lei Maria da Penha (Lei 11.340) & 2006 \\
\hline Costa Rica & Lei de penalização da violência contra as mulheres & \multirow{3}{*}{2007} \\
\hline Venezuela & $\begin{array}{l}\text { Lei Orgânica sobre o direito das mulheres a uma vida livre de } \\
\text { violência }\end{array}$ & \\
\hline México & $\begin{array}{l}\text { Lei Geral de Acesso das Mulheres a uma vida livre de } \\
\text { violência }\end{array}$ & \\
\hline Guatemala & $\begin{array}{l}\text { Lei contra o feminicídio e outras formas de violência contra a } \\
\text { mulher }\end{array}$ & \multirow[t]{2}{*}{2008} \\
\hline Colômbia & Lei 1257 de Violência contra as mulheres & \\
\hline Argentina & $\begin{array}{c}\text { Lei de proteção integral para prevenir, sancionar e erradicar a } \\
\text { violência contra as mulheres nos âmbitos em que } \\
\text { desenvolvem suas relações interpessoais. }\end{array}$ & 2009 \\
\hline
\end{tabular}

Fonte: adaptado (e com tradução aproximada pelos autores) de Fernández (2012)

Estas leis representam o avanço em políticas locais, mas não abrangentes em toda a macrorregião, dos esforços para a eliminação da violência contra mulheres.

Com documentos influentes para todo o mundo, o ponto máximo dos esforços da ONU foi a criação em 2010 do ONU Mulheres. Atualmente, a ONU Mulheres é uma excelente base de dados e de publicações sobre a violência contra a mulher, especialmente nos espaços da macrorregião em estudo.

A CEPAL através da Divisão de Assuntos de Género para a América Latina e o Caribe e da Comissão Econômica para a América Latina e Caribe também se configura como espaço decisivo nos estudos sobre a violência de gênero, por exemplo, dados de observatórios voltados para a eliminação da violência de gênero, dados estatísticos sobre a violência contra mulheres etc. (PONTE, 2017; CEPAL, 2019; 2020).

Outra importante instituição internacional é o CLADEM - Comité de América Latina y el Caribe para la Defensa de los Derechos de la Mujer.

Em relação às redes, observatórios, Declarações e programas para eliminação da violência contra a mulher, na macrorregião, podem ser citados: Mapa da violência contra mulheres; Red Chilena contra la violencia hacia las mujere; Red SEMLAC - Servicio de noticias de la mujer de latinoamerica y el Caribe; ACNUR; CAIRO+10; Convenção de Belém do Pará (Convenção Interamericana para prevenir, sancionar e erradicar a violência contra a mulher); Programa "!Ni una más;", apresentado por Montaño (2007).

Mas, como bem aponta Fernandéz (2012) há limitações no uso dos dados estatísticos destas instituições internacionais sobre a violência de gênero na AL e CA, particularmente, 
dados sobre mortes, agressões, as diversas denúncias e condenações impetradas por juizados locais, regionais e por países, por exemplo.

Os dados são dispersos a princípio, segundo Fernández (2012). O principal fator é a falta de sensibilidade ou interesse pelo assunto dos órgãos públicos de gestão da questão. Contudo, são estes dados, que colocam a macrorregião sob constante alerta com relação à efetividade de políticas já desenvolvidas e aprovadas, mas que se encontram em não consonância com os acordos internacionais, ou seja, não se efetivam. Isso se deve às elevadas demandas por tais políticas, resultantes, sobretudo de mortes de mulheres, feminicídio - termo jurídico (LAGARDE, 2004) - e de políticas de enfrentamento.

A demarcação histórica a partir da possibilidade 1 se desmembram algumas "subpossibilidades", considerando as ponderações embasadas na história, sob uma perspectiva foucaultiana, importantíssima e inovadora, para a área da Educação Sexual.

- A "sub-possibilidade 1" se direciona às leis dos países da macrorregião e o histórico de suas efetividades a partir dos grandes órgãos da ONU, CEPAL e CLADEM, iniciando-se por estes e expandindo-se a outras instituições no território. Para o caso brasileiro, por exemplo, um estudo histórico sobre efetividades históricas da Lei Maria da Penha. A área da Educação Sexual encontrará muitos trabalhos, em diversas áreas do conhecimento, especialmente, no Direito, que poderão subsidiar um histórico da violência de gênero no Brasil antes e depois desta Lei. O que poderá, por exemplo, ser um estudo comparativo com leis semelhantes a Lei Maria da Penha, em outros países. Portanto, estudos de investigações comparativas em Educação Sexual.

- A "sub-possibilidade 2" relaciona-se a investigações nas produções das redes, das declarações oriundas de eventos na macrorregião, bem com observatórios da violência de gênero; políticas locais, relatórios anuais de delegacias da mulher, por exemplo; estatísticas de mortes de mulheres e meninas, estatísticas de violência de gênero em suas diversas formas, o que incluiria, por exemplo, a violência de gênero contra travestis e transexuais.

Se defende que a possibilidade 1 seja, pelo menos, um ponto de partida mais geral e, ao mesmo tempo, mais "adequado" em relação a uma certeza de "inflexão" em uma possível construção histórica da violência de gênero, o que se exclui, como já se afirmou, a construção de histórico antes da chegada europeia na macrorregião, o que demandaria um estudo etnográfico, arqueológico, a princípio. 


\section{Possibilidade 2: o histórico do colonialismo europeu na macrorregião e algumas teorias}

Tão mais complexo que a possibilidade 1, a busca de uma construção do histórico da violência de gênero a partir do colonialismo europeu e as teorias concernentes e concorrentes à esta violência, estudada, principalmente, pelas militantes e pesquisadoras feministas, encontram em nossa proposta histórica foucaultiana uma questão importante: só podemos falar de uma violência contra as mulheres após a colonização? E antes? E, em relação aos povos e nações que aqui habitavam? Retoma-se, nossa questão sem resposta.

Na proposta histórica que se está a construir para a área da Educação Sexual, não se pode considerar que a macrorregião só veio a existir com os europeus colonizadores. Aqui já tinha vida, havia gente. Uma saída possível seria, na atualidade, se buscar junto aos ascendentes indígenas, de todos os povos e nações, em toda América Latina e Caribe, as formas pelas quais viviam as mulheres e quais os seus discursos, suas falas ascendentes sobre sexo, sobre sexualidade, sobre os papeis e funções das mulheres.

Já se percebe, por este ângulo da questão, o quão audacioso é o projeto de pesquisa na área da Educação Sexual, em construir uma história foucaultiana em que a violência de gênero não pode ser simplificada e, desta forma, um caminho possível é a regressão, partindo da atualidade, século XXI, e buscar nos registros a ampliação, tempo a tempo, lugar a lugar, contexto a contexto, em contínuas fragmentações e pontos de inflexão, atemporais, sobretudo, na tentativa, ainda mínima e reduzida de uma possível história da violência de gênero dos tempos anteriores à colonização. Simultaneamente a essa busca "regressora", que se organizem teorias e teorizações inovadoras que expliquem, "daqui" e "por aqui" a "nossa" história, a história contada, primeira e exclusivamente, por mulheres, "mulheres do sul" - parafraseando Boaventura de Sousa Santos. O protagonismo feminino sobre si.

Ao lado desta proposta "utópica", a princípio, se pode pensar nesta "Possibilidade 2" estudar, aplicar e aprofundar (quem sabe, alterar) as teorias sobre a violência de gênero já construídas, sobretudo, nas Ciências Sociais e Antropologia, que podem explicar ou dar uma orientação básica para um histórico da violência de gênero na macrorregião.

Veja o Quadro 2.

Quadro 2 - Algumas teorias para o estudo da violência de gênero na macrorregião

\begin{tabular}{|l|l|}
\hline \multicolumn{1}{|c|}{ TEORIA } & \multicolumn{1}{c|}{ AUTORAS(ES) } \\
\hline Patriarcado & Muraro (1995); Saffioti; Almeida \\
& (1995); Amorós (1991) \\
\hline
\end{tabular}

RPGE- Revista on line de Política e Gestão Educacional, Araraquara, v. 24, n. esp. 3, p. 1809-1824, nov. 2020. e-ISSN:1519-9029 DOI: https://doi.org/10.22633/rpge.v24iesp3.14281 
Fonte: Elaborado na pesquisa

\begin{tabular}{|l|l|}
\hline Colonialidade do poder & Quijano (1992) \\
\hline Colonialidade de gênero & Lugones (2008) \\
\hline Epistemologias do Sul & Santos; Meneses (2010) \\
\hline Perspectiva sociológica geral & Pita (2015); Modena (2016) \\
\hline
\end{tabular}

Antes mesmo de teorias do colonialismo e suas variantes, sabe-se e, entende-se, neste trabalho, que a violência de gênero tem sua raiz nas desigualdades históricas entre homens e mulheres. Ou seja, relações estruturais de desigualdade, seja por etnia, cultura ou condição social. Desta forma, a ideia de cultura deve perpassar as historicidades da violência de gênero na América Latina e Caribe, o que implica aos pesquisadores(as) da Educação Sexual uma maior atenção aos detalhes e contribuições da etno-história e da antropologia, sobretudo, dos estudos feministas, produzidos por mulheres, na macrorregião

\section{Conclusão}

Apontar o início dos estudos de uma possível história da violência de gênero na macrorregião, a partir, unicamente, das produções feministas acadêmicas nas áreas das ciências sociais e antropologia e, no âmbito da militância política, dede os anos 1970, por exemplo, seria um trabalho de muito esforço e demandaria muito tempo dos pesquisadores da área da Educação Sexual. Além do que se arriscaria a desconsiderar a ampla produção na AL e CA, anterior a este período, ainda que fossem pontuais.

Ter como ponto de partida os anos 1990, data que marca a inserção "tardia" - se repete veemente essa observação - na pauta da ONU e outros órgãos do tema da violência de gênero. A elaboração de políticas de enfrentamento parece indicar uma possibilidade mais plausível como indicadores para pesquisas de planejamento na área da Educação Sexual.

As duas possibilidades apresentadas neste texto, são, desta forma, uma pequena contribuição de demarcação histórica, numa perspectiva foucaultiana, em que se pondera que há, sim, uma possibilidade de se falar em um histórico da violência de gênero, no âmbito das políticas, mas também, no âmbito das práticas sociais que permitam, não mais uma "fala(as)" ou discurso(s) apenas nos âmbitos "fechados" do movimento feminista mundial, mas se passa a considerar, amplamente, o debate, para além deste movimento, ou seja, alinhado a outros movimentos sociais, sobretudo aqueles voltados ao tema da sustentabilidade e, mais especificamente, para âmbitos do currículo escolar e de espaços não escolares em Educação Sexual para a macrorregião, fundamentado no escopo atual do que se convenciona chamar, 
"politicamente" de empowerment (empoderamento feminino) ou empoderamento de meninas e mulheres.

Nenhuma das duas possibilidades são caminhos fáceis para nossa proposta de pesquisa mais ampla para a Educação Sexual, qual seja a de discutir e inovar o tema da violência de gênero nesta macrorregião, ao possuir, para isso, os aportes do discurso e do poder em Michel Foucault. Mas são caminhos de pesquisa complexos e possíveis.

A resposta à pergunta desta pesquisa é “Sim”. Sim, há um caminho inicial possível para o histórico da violência de gênero na América Latina, que possa ser iniciado, com os dados históricos e estatísticos dos órgãos internacionais e, portanto, o trabalho de pesquisas estatísticas, de observatórios, da organização de dados, que irão permitir "regredir" o tempo e demarcar o que Michel Foucault chama de "descontinuidades" da História. Do mesmo modo, a busca de relatórios, de dados sobre a violência etc.

Outro caminho: as bases e fundamentos dados por autoras(es) da macrorregião, em artigos, capítulos de livros e livros, ancorados na ONU, na CEPAL ou universidades, que apontam as questões do colonialismo europeu na América Central, no Caribe e na América do Sul, majoritariamente, dominados pelos espanhóis, tendo, os portugueses, no caso, colonizando o Brasil e, sobretudo no Caribe, com influências holandesas, inglesas, francesas (particularmente, no Sul, na Guiana).

O histórico da macrorregião encontra outro desafio que é a particularidade de cada lugar: o histórico é possível, num viés foucaultinano de História - concepção deste trabalho -, se iniciar pelos discursos estatísticos e suas implicações culturais e antropológicas, sobretudo.

As(os) estudiosas(os) nesta área terão que se dispor a organizar esta historicidade foucaultiana da violência de gênero sob um "espírito" - conceito de Gaston Bachelard descontínuo da história: começar pela contemporaneidade, tendo como marco, as políticas internacionais para a macrorregião e, na medida do possível, ir construindo as particularidades em cada Estado-Nação, identificando as similaridades, as comparações, os distanciamentos e as diferenças.

Se do ponto de vista do início - a partir das teorias do colonialismo - a violência de gênero possui um elo comum, o desenvolvimento e atualidades da questão, pelo menos, aparentemente, não se caracterizam por pontos de inflexão e pontos comuns, a não ser, o enfrentamento em si e a política, por exemplo, da ONU, Agenda 2030, no empoderamento de meninas e mulheres, etc.

Um desafio, a partir do histórico do desenvolvimento do tema da violência de gênero na macrorregião é a construção de programas sociais para homens e mulheres, numa proposta de 
Educação Sexual escolar e não escolar, unindo ações multifacetadas da administração pública numa proposta de prevenção das violências.

Outros encaminhamentos de subsídios para as pesquisas em Educação Sexual sobre a violência de gênero na macrorregião é organizar o projeto ou programa de pesquisa, da possibilidade 2, inicialmente a partir dos estudos e investigações produzidos na macrorregião e por investigadores(as) nativos(as) e delimitar no histórico destas produções que emergem, sobretudo das ciências sociais, o momento de inserções de políticas internacionais, que foram "tardias" e, nesse exercício "arqueológico" interpretar e descrever a atualidade, com as efetividades de enfrentamento da violência de gênero, a violência contra meninas e mulheres.

Que a proposta do "dispositivo de violência de gênero" aqui apontado possa ser uma motivação de estudos na área da Educação Sexual, como uma proposta de “possibilidade 3" na construção de uma história da violência de gênero antes da "presença europeia", antes da colonização, com apoio na etno-história e na antropologia - quem sabe, na arqueologia.

Em conjunto, as duas possibilidades propostas e a terceira possibilidade, como "dispositivo" produzem impactos formativos tanto para o currículo escolar quanto para os espaços não escolares, na luta, pelo fim, sobretudo, da violência e do feminicídio de meninas e mulheres. Que este texto contribua ao debate do empoderamento feminino nos estudos da Educação Sexual.

\section{REFERÊNCIAS}

AMORÓS, C. Hacia una crítica de la razón patriarcal. Anthropos; Madrid: 1991.

BENAVENTE, M. C.; VALDÉS, A. Políticas públicas para la igualdad de género: un aporte a la autonomía de las mujeres. Santiago: Naciones Unidas, CEPAL, 2014.

BOTT, S; MORRISON, A.; ELLSBERG, M. Cómo abordar la violencia de género en América Latina y el Caribe: revisión crítica de las intervenciones. Washington, DC: Banco Mundial, 2005. (Breve, n. 60)

CEPAL. NACIONES UNIDAS. La autonomia de las mujeres em escenarios económicos cambiantes. Santiago, Chile: CEPAL, 2019.

CEPAL. NACIONES UNIDAS. Panorama social da América Latina, 2019. Resumo executivo. Santiago, Chile: CEPAL, 2020.

CORRÊA, M. Morte em família. São Paulo: Brasiliense, 1983. 
CRUZ, J. M. et al. De la guerra al delito: evolución de la violencia em El Salavador. In: LONDOÑO, J. L. et al. Asalto al desarrollo: violencia em America Latina. Banco Interamericano de Desarrollo. Whashington, D.C., 2000.

FERNÁNDEZ, I. G. A violência de gênero no contexto da América Latina. Pensar, Fortaleza, v. 17, n. 1, p. 161-194, jan./jun. 2012. Disponível em:

https://www.researchgate.net/publication/315051438_A_violencia_de_genero_no_contexto_d a_America_Latina. Acesso em: 13 jun. 2020.

FOUCAULT, M. A ordem do discurso. São Paulo: Loyola, 2004.

FOUCAULT, M. História da sexualidade I: A vontade de saber. 13. ed. Rio de Janeiro: Graal, 2004.

FOUCAULT, M. Arqueologia do saber. 7. ed. Rio de Janeiro: Forense Universitária, 2008.

FREGOSO, R. L.; BEJARANO, C. (Org.). Feminicídio en américa latina. México, DF: Unam/CIIECH/Red de Investigadoras por la Vida y la Libertad de las Mujeres, 2010.

LAGARDE, M. Violencia de género y paz social unidas por la vida y la libertad de las mujeres. In: Asociación seminario mujer Latinoamericana - Mujer Andaluza. 10 años de historia 1995-2005: hilando redes. Huelva, 2004. p. 23-34.

LERNER, G. La creación del patriarcado. Barcelona: Crítica, 1986.

LUGONES, M. Colonialidade e gênero. Tábula Rasa (online), n. 9, p. 73-102, 2008.

Disponível em: http://www.scielo.org.co/scielo.php?pid=S1794-

24892008000200006\&script=sci_abstract\&tlng=pt. Acesso em: 14 set. 2020.

MODENA, M. R. (Org.). Conceitos e formas de violência. Caxias do Sul: Educs, 2016.

MONTAÑO, S. (Dir.). ¡Ni una más; El derecho a vivir una vida libre de violencia en América Latina y el Caribe. Antiguo Cuscatlán: UNFPA, 2007.

MONTEIRO, S. A. S.; SILVA, C. R.; RIBEIRO, P. R. M. Investigação da violência de gênero na América Latina e Caribe: pequena revisão da literatura (2017-2019). Revista On Line de Gestão e Política Educacional, Araraquara, v. 24, n. 2, p. 650-667, maio/ago. 2020. DOI: https://doi.org/10.22633/rpge.v24i2.13812

MURARO, R. M. A mulher no terceiro milênio. 3. ed. Rio de Janeiro: Rosa dos Tempos, 1995.

OLIVEIRA, R. D. Elogio da diferença: o feminino emergente. São Paulo: Brasiliense, 1999. PITA, I. H. Violencia de Género: una mirada desde la sociología. 1. ed. Cuba: Editorial Científico-ténica, 2015.

PONTE, N. B. La agenda 2030 y la agenda regional de género: Sinergias para la igualdad en América Latina y el Caribe. Santiago: Naciones Unidas, CEPAL, 2017.

PRIORE, M. Del. (Org.). História das mulheres no Brasil. São Paulo: Contexto, 2012. 
QUIJANO, A. Colonialidad, modernidad/racionalidade. Perú Indígena, v. 13, n. 29, p. 1129, 1992. Disponível em: https://www.lavaca.org/wp-content/uploads/2016/04/quijano.pdf. Acesso em 09 set. 2020.

SAFFIOTI, H. I. B.; ALMEIDA, S. S. Violência de gênero: poder e impotência. Rio de Janeiro: Livraria e Editora Revinter Ltda, 1995.

SAFFIOTI, H. I. B. Gênero, patriarcado, violência. São Paulo: Fundação Perseu Abramo, 2004.

SANTOS, B. S.; MENESES, M. P. (Org.). Epistemologias do sul. São Paulo, Cortez, 2010.

SILVA, C. R. Violência de gênero no Brasil e na América Latina: um enfoque psicanalítico, a produção de conhecimento e perspectivas de enfrentamento. Doxa: Rev. Bras. Psico. e Educ., v. 20, n. 1, jan./jun. 2018. DOI: https://doi.org/10.30715/rbpe.v20.n1.2018.11284

STREY, M. N.; AZAMBUJA, M. P. R.; JAEGGER, F. P. (Org.). Violência, gênero e políticas públicas. Porto Alegre: EDIPUCRS, 2004.

\section{Como referenciar este artigo}

SILVA, C. R.; RIBEIRO, P. R. M.; MONTEIRO, S. A. S. Por um histórico da violência de gênero na América Latina e Caribe: "possiblidades" para as pesquisas em educação sexual. Revista on line de Política e Gestão Educacional, Araraquara, v. 24, n. esp. 3, p. 1809-1824, nov. 2020. e-ISSN:1519-9029. DOI: https://doi.org/10.22633/rpge.v24iesp3.14281

Submetido em: 10/01/2020

Revisões requeridas: $20 / 07 / 2020$

Aprovado em: 30/10/2020

Publicado em: $30 / 11 / 2020$ 